\title{
SISMOESTRATIGRAFIA RASA DA PLATAFORMA CONTINENTAL DE CABO FRIO - ARARUAMA - RJ
}

\author{
Lucia Artusi ${ }^{1}$ e Alberto Garcia de Figueiredo Jr. ${ }^{2}$
}

Recebido em 17 fevereiro, 2005 / Aceito em 20 março, 2007 Received on February 17, 2005 / Accepted on March 20, 2007

\begin{abstract}
Seismic sections on the continental shelf adjacent to Araruama lagoon, Rio de Janeiro state, allowed the mapping of the acoustic basement and the seismic analysis of the sedimentary cover until the middle continental shelf $(\sim 110 \mathrm{~m})$. The acoustic basement outcrops in the northwest sector of the study area, while it is buried under $200 \mathrm{~m}$ of the sediments in the southeast sector (middle shelf). Four seismic sequences (SI, SII, SIII and SIV) limited by four unconformities (DI, DII, DIII and DIV) were identified in the sedimentary section recovering the acoustic basement. Correlation between the seismic analysis and previous studies in the area suggest that the sequence deposition started in the Upper Miocene.
\end{abstract}

Keywords: marine Quaternary; shallow seismic; Cabo Frio High; paleochannels.

RESUMO. Seções sísmicas da plataforma continental adjacente à laguna de Araruama-RJ permitiram o mapeamento do embasamento acústico e a análise sísmica da cobertura sedimentar até a plataforma continental média ( $100 \mathrm{~m}$ ). 0 embasamento acústico aflora no setor noroeste da área de estudo enquanto no setor sudeste (plataforma média) ele está recoberto por $200 \mathrm{~m}$ de sedimentos. Quatro seqüências sísmicas (SI, SII, SIII e SIV) limitadas por quatro descontinuidades (DI, DII, DIII e DIV) foram identificadas na seção sedimentar que recobre o embasamento acústico. Correlações entre as análises sísmicas e estudos anteriores na região sugerem que a deposição da seqüência teve início no Mioceno Superior.

Palavras-chave: Quaternário marinho; sísmica rasa; Alto do Cabo Frio; paleocanais.

\footnotetext{
1 Instituto de Estudos do Mar Almirante Paulo Moreira - IEAPM, Rua Kioto, 253, Praia dos Anjos, 28930-000 Arraial do Cabo, RJ, Brasil. Telefone: (22) 2622-9014; Fax: (22) 2622-9093 -E-mail: lucia_artusi@yahoo.com.br /14a@ieapm.mar.mi.br

${ }^{2}$ Laboratório de Geologia Marinha - LAGEMAR/UFF, Av. Litorânea s/nº, Bairro Praia Vermelha, 24210-340 Niterói, RJ, Brasil. Telefone: (21) 2629-5938; Fax: (21) 2629-5931 - E-mail: alberto@igeo.uff.br
} 


\section{INTRODUÇÃo}

A área pesquisada localiza-se na plataforma continental de Cabo Frio ao largo da laguna de Araruama, entre 30 m e 145 m de profundidade (Fig. 1).

Uma das principais características desta área é a abrupta mudança na direção da linha de costa de E-W para NE-SW, também observada na batimetria. Esta configuração morfológica é apontada como um dos fatores responsáveis, juntamente com a ação dos ventos de NE, mais intensos no verão, pela ressurgência das águas frias e ricas em nutrientes oriundas da Antártica.

0 objetivo deste trabalho é estudar o pacote sedimentar e identificar a profundidade do embasamento acústico da área de estudo, visando compreender a sua história evolutiva.

\section{ESTUDOS ANTERIORES}

A área de estudo encontra-se na região do Alto do Cabo Frio, onde Asmus (1984) observou espessura de até $2 \mathrm{~km}$ de sedimentos, baseando-se em perfis sismográficos. Posteriormente Viviers \& Azevedo (1988), analisando as curvas de isovalores dos mapas paleobatimétricos, feitos a partir de mapas paleoecológicos, verificaram que esta sedimentação teve início a partir do Cretáceo Superior.

Dias (1997) a partir de interpretações de mapa gravimétrico "ar-livre", distinguiu uma abrupta interrupção das anomalias gravimétricas positivas, correspondendo às Bacias de Campos e de Santos, dando lugar a baixos gravimétricos reforçando a presença de crosta Pré-Cambriana do Alto do Cabo Frio. Geneticamente 0 alinhamento estrutural E-W, que caracteriza 0 alinhamento da linha de costa nesta região, foi relacionado à Zona de Fratura do Rio de Janeiro (ZFRJ) (Kumar et al., 1977) e, posteriormente, à Zona de Fratura Martim Vaz (ZFMV) (Alves et al., 1997). Outros alinhamentos estruturais que se destacam na porção emersa desta área referem-se às estruturas ENE-WSW do Cinturão Ribeira e os de direção NW-SE, descritos por Fonseca et al. (1984) como característicos de um bloco cratônico pré-Brasiliano (Complexo Região dos Lagos) 0 qual possivelmente está correlacionado à extremidade ocidental do cráton do Congo. As rochas vulcânicas alcalinas observadas principalmente na ilha do Cabo Frio foram datadas em 52,1 $\pm 0,8 \mathrm{Ma}$ (Ferrari, 2001) e resultam de um segundo evento tectônico importante nesta área.

As espessuras do pacote de sedimentos determinadas por Azevedo Jr. (1991), a partir de dados sísmicos e de poços nos perfis C e D (Fig. 1) foram de cerca de $130 \mathrm{~m}$ e $785 \mathrm{~m}$ respectivamente. Nestes perfis foram mapeadas sete seqüências a partir do Cenozóico Superior, com base em nanofósseis calcáreos.
Silva (1992) com base em informações de poços e de seções sísmicas exploratórias da borda da plataforma na altura do Cabo de São Tomé identificou dois refletores com extensão regional, denominando-os marco "Cinza" e marco "P". 0 primeiro datado do Neo-Mioceno ao Eo-Plioceno, o segundo, de idade MesoPleistocênica (aproximadamente 500.000 anos).

Lopes (2004) por sua vez, analisando perfis sísmicos mono e multicanal na plataforma continental sul da Bacia de Campos, identificou quatro unidades sísmicas (U1, U2, U3, U4) limitadas por cinco superfícies discordantes (S1, S2, S3, S4, S5). Foi estimada a idade Quaternária para o intervalo entre as unidades U1 e U4, com base no trabalho de Silva (1992).

\section{METODOLOGIA}

\section{Dados pretéritos}

Para 0 estudo da morfologia da plataforma continental ao largo da laguna de Araruama, foram digitalizadas as Folhas de Bordo do Centro de Hidrografia da Marinha (CHM). Mapas batimétrico e de variações do gradiente foram confeccionados a partir de dados batimétricos espaçados, em média, de 950 m, obtidos pela vetorização de Folhas de Bordo com escala 1:100.000. Para tal, foi usando como interpolador o método Single grid do programa Oasis Montaj da Geosoft Inc (versão 5.1.8).

Os dados sísmicos pretéritos utilizados são os das comissões GEOMAR XVI/80, CENTRATLAN I/81 e GEOMAR XX/82.

\section{Coleta de novos dados sísmicos}

Os parâmetros usados na aquisição dos dados sísmicos possibilitaram 0 estudo do pacote de sedimentos com espessura de até $120 \mathrm{~m}$. Para a aquisição de $210 \mathrm{~km}$ de dados sísmicos de reflexão foram utilizados uma fonte, um banco de capacitores e um gerador de sinais da EG\&G, um sparker com três eletrodos e uma enguia de hidrofones com oito elementos. Os dados sísmicos foram gravados usando o gravador da Empresa CodaOctopus que gravou, simultâneamente, as informações de navegação obtidas por GPS e integradas pelo sistema Hypack da Coastal Oceanographics. A velocidade do navio durante o levantamento foi de cinco nós, 0 sparker disparando com uma potência de $500 \mathrm{~J}$, com intervalo de disparo de $500 \mathrm{~ms}$ e largura do pulso de $60 \mathrm{~ms}$. 0 sparker ficou posicionado a $15 \mathrm{~m}$ de distância da popa do AvPqOc Diadorim, enquanto que a enguia de hidrofones permaneceu a uma distância de cerca de $35 \mathrm{~m}$ da popa, no bordo oposto. 


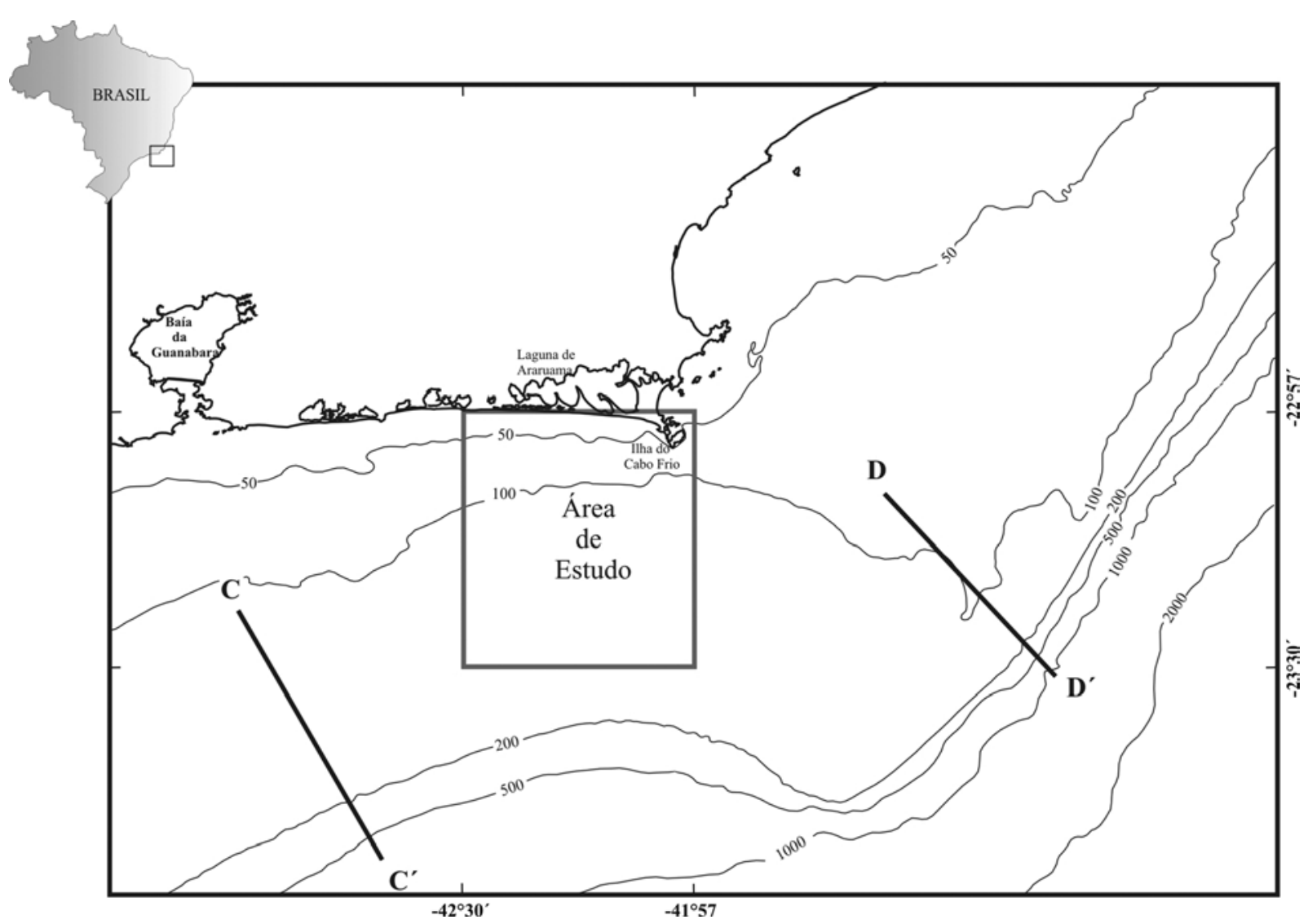

Figura 1 - Localização da área de estudo, entre os perfis C-C’e D-D’de Azevedo Jr. (1991), que delimitam o Alto do Cabo Frio.

\section{RESULTADOS E DISCUSSÃO}

\section{Embasamento acústico}

A análise dos perfis sísmicos possibilitou delimitar o embasamento acústico nas plataformas interna e média da área de estudo. Este embasamento acústico encontra-se aflorante ao longo de $850 \mathrm{~m}$ na porção oeste próximo da isobatimétrica de $45 \mathrm{~m}$ (Fig. 2), conforme já descrito por Muehe \& Carvalho (1993). 0 embasamento acústico aprofunda-se tanto para leste, atingindo cerca de $60 \mathrm{~m}$ abaixo do pacote sedimentar nas proximidades da ilha do Cabo Frio, como para sul, na plataforma média, onde foi detectado sobreposto a $85 \mathrm{~m}$ de sedimentos. A inexistência de perfis sísmicos que penetrassem nos sedimentos além dos 120 m, na plataforma externa, não permitiu o mapeamento do embasamento acústico nesta área.

0 embasamento acústico, quando analisado sob o enfoque morfológico apresenta-se relativamente suave em praticamente toda a região, exceto ao largo da ilha do Cabo Frio na seção BC da comissão CENTRATLAN I (Fig. 2), onde foram observadas declives mais íngremes e espessuras de sedimentos de até $200 \mathrm{~m}$.
Tanto a morfologia do embasamento acústico como a localização de seu afloramento na porção NW da área de estudo permitiram sugerir, à semelhança do que já havia sido apresentado por Gorini et al. (1984), que esse embasamento acústico é composto por rochas pré-Cambrianas semelhantes às do continente emerso, neste caso, as rochas do Complexo Região dos Lagos. A morfologia mais irregular observada nas proximidades da ilha do Cabo Frio, distinta do restante da área de estudo (Fig. 2), sugerem que ele seja composto de rochas vulcânicas similares às que ocorrem na ilha do Cabo Frio.

\section{Seqüências sísmicas}

A interpretação dos perfis transversais às isobatimétricas possibilitou 0 reconhecimento de quatro seqüências sísmicas (SI, SII, SIII e SIV), semelhantes às identificadas por Lopes (2004) em seu estudo na plataforma da Bacia de Campos (Fig. 3). Estas seqüências estão separadas por quatro discordâncias, três delas claramente erosivas, as DI, DII e DIII; a mais rasa, DIV, sem feições erosivas identificadas nos perfis estudados. 


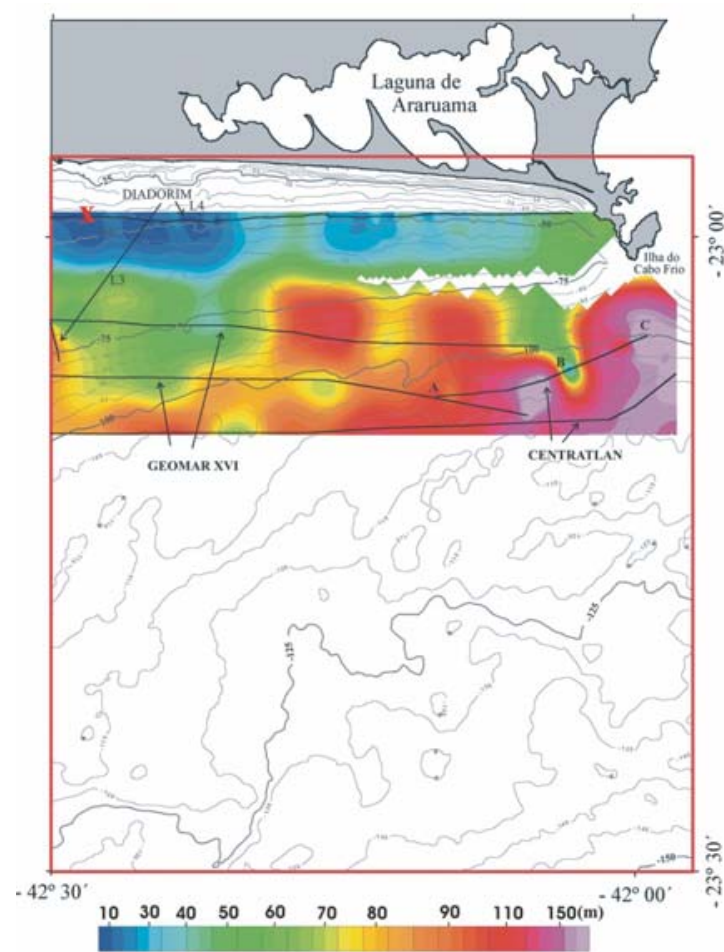

(A)

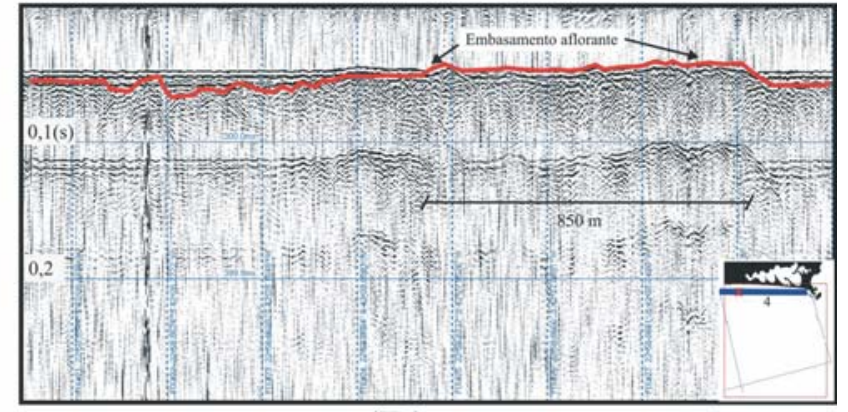

(B)

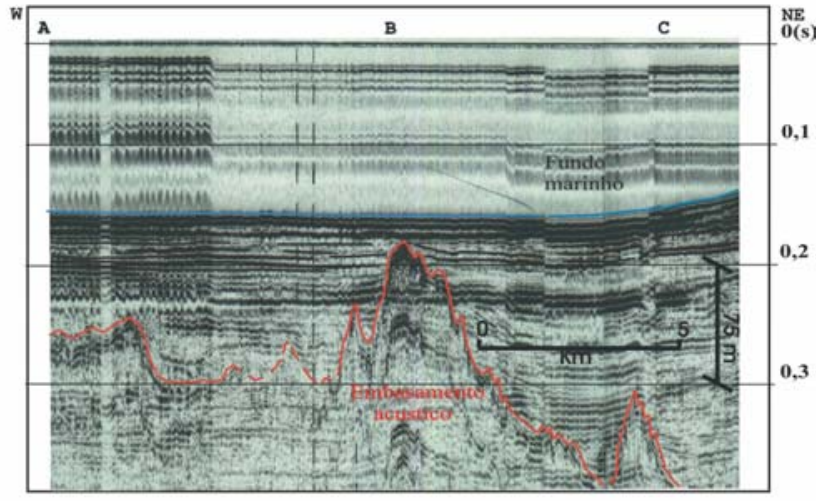

(C)

Figura 2 - (a) Mapa de espessura de sedimentos identificado a partir da interpretação das seções sísmicas das comissões GEOMAR XVI, CENTRATLAN I e Diadorim. (X) Embasamento aflorante. Pontos A, B e C - indicados no perfil sísmico da Fig. 2(c); (b) Embasamento aflorante indicado no ponto (X) da Fig. 2(a); (c) Perfil sísmico da comissão CENTRATLAN mostrando o embasamento acústico. Nas seções sísmicas, o tempo é duplo.

A análise da geometria dos refletores do pacote sedimentar possibilitou distinguir dois sistemas distintos. 0 primeiro composto pelas seqüências inferiores SI e SII, com clinoformas mergulhantes com alto ângulo em direção ao talude e limitadas por superfícies claramente erosivas (DI, DII e DIII). 0 pacote sedimentar superior, composto pelas seqüências SIII e SIV, com clinoformas suavemente inclinadas em direção ao talude e separadas entre si pela discordância DIV.

Com o intuito de inferir as idades das seqüências sísmicas SI, SII, SIII e SIV, comparou-se os dados desta pesquisa com os encontrados por Azevedo Jr. (1991) em seu estudo dos perfis C-C e D-D' (Fig. 1) e com os resultados de Silva (1992), esquematicamente sintetizados na Figura 4. Os elementos usados na comparação foram a espessura do pacote sedimentar e a sua estruturação interna.

Ao buscar uma possível correlação com o trabalho de Silva (1992), foi verificado que a descontinuidade DII, por sua característica marcadamente erosiva, poderia ser correlacionada ao marco Cinza (Neo-Mioceno a Eo-Plioceno). A seqüência SI, desta forma, seria correlata à seqüência 6 descrita por Azevedo Jr. (1991) com idade Neo-Miocênica. Se observarmos a curva de variação do nível do mar de Vail et al. (1977), a formação da seqüência I pode ser relacionada à descida do nível do mar que começou após o máximo de + 65 m ocorrido há cerca de $5 \mathrm{Ma}$. Da mesma forma, a descontinuidade erosiva DII pode estar relacionada ao máximo rebaixamento do nível do mar indicado na curva de Vail et al. (1977) de cerca de $160 \mathrm{~m}$, com idade de aproximadamente $3 \mathrm{Ma}$.

A seqüência SII, por sua vez, também com clinoformas progradantes com alto ângulo de mergulho em direção ao talude, é limitada no seu topo por uma discordância nitidamente erosiva (DIII) (Fig. 3). Valendo-se de inferências feitas a partir do trabalho de Silva (1992), a seqüência SII pode estar relacionada ao evento de descida do nível do mar que antecedeu à formação do marco "P", ao qual foi atribuída idade de 500.000 anos. Ao se observar a curva de Vail et al. (1977), foi verificada outra possibilidade para a formação da seqüência II, que pode estar relacionada à descida do nível do mar do Pleistoceno médio (cerca de 1,5 Ma.), 
( B )

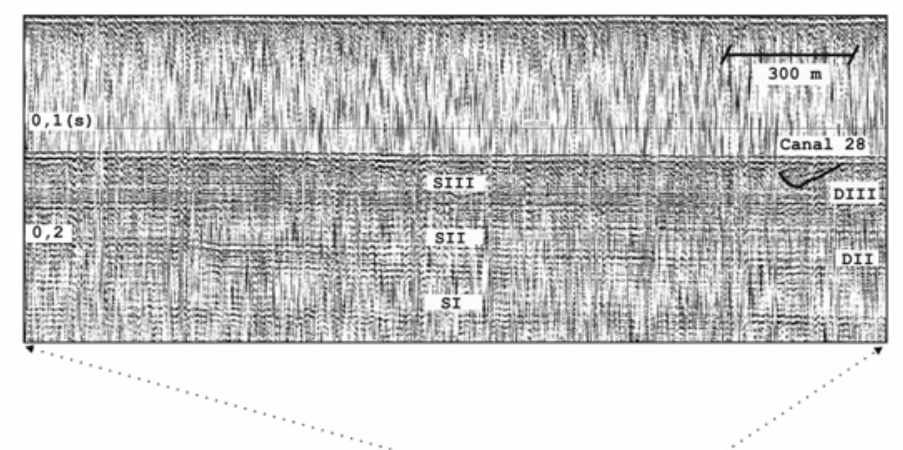

(C)

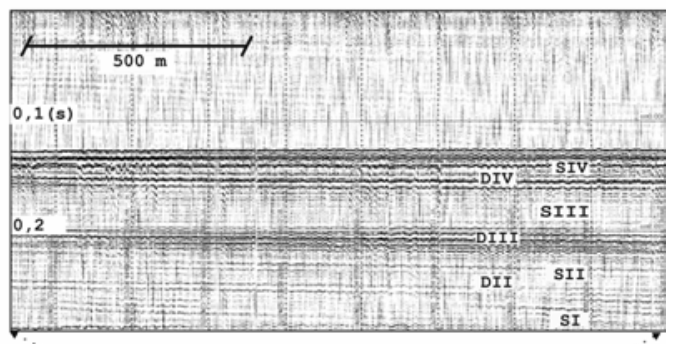

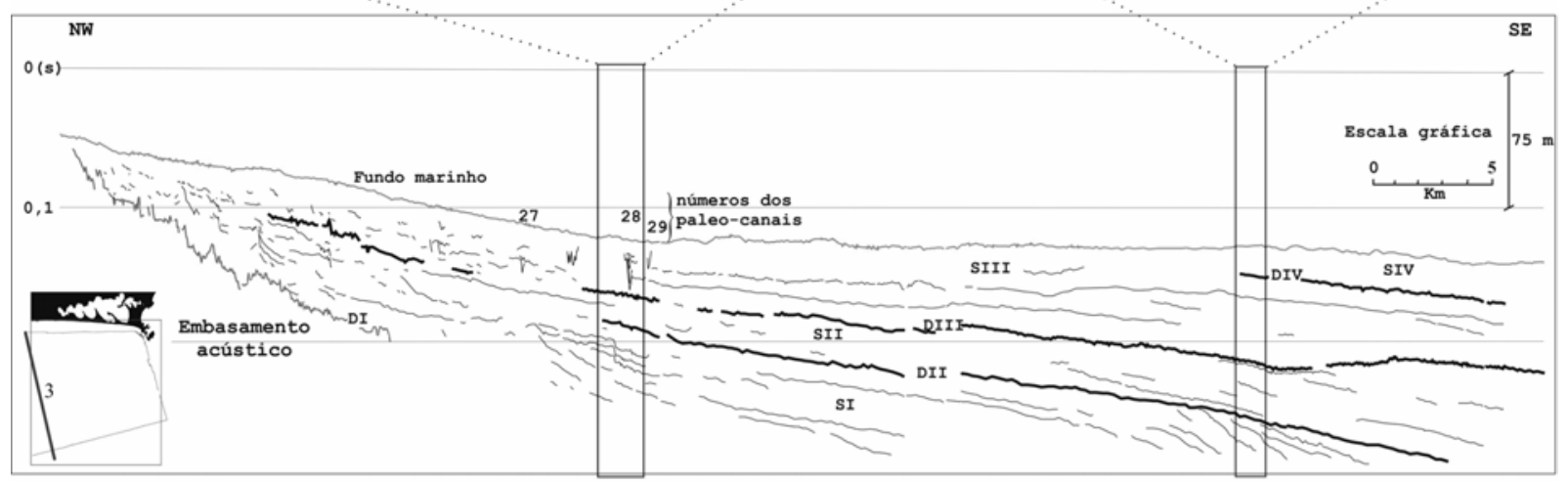

(A)

Figura 3 - (a) Interpretação da linha 3 da comissão Diadorim. (a) Seção sísmica mostrando as seqüências I, II e III e o paleocanal nº 28. (b) Seção sísmica mostrando as sequiências I, II, III e IV. Nas seções sísmicas, o tempo é duplo.

quando o máximo rebaixamento alcançou cerca de $120 \mathrm{~m}$. Caso se confirme a hipótese de a DIII ser o prolongamento do marco "P", então os sedimentos depositados durante o rebaixamento do nível do mar há cerca de 1,5 Ma. podem ter sido totalmente removidos, ou então, a seqüência relativa a este evento pode não ter sido detectada nos perfis analisados.

A seqüência SIII possui clinoformas progradando suavemente em direção ao talude (Fig. 3) o que pode indicar tanto uma baixa taxa de descida do nível do mar sem que tenha havido subsidência do fundo significativa, como uma taxa de subsidência levemente maior do que a descida do nível do mar. A discordância DIV é uma superfície refletora que separa as seqüências SIII e SIV e com elas é concordante, é observada no pacote sedimentar da plataforma externa a partir da isobatimétrica de $115 \mathrm{~m}$ a $120 \mathrm{~m}$ aproximadamente. A discordância DVI, por não possuir evidências de erosão, pode representar uma estabilização do nível do mar. Pela observação das curvas de variação do nível do mar compiladas por Molina et al. (2000), foi considerada a possibilidade de a discordância DIV estar relacionada ao rebaixamento do nível relativo do mar após 123.000 anos A.P. Aceitando-se esta hipótese e considerando-se que a seqüência SIII, na área estudada, possui cerca de $40 \mathrm{~m}$ de espessura, então a taxa de deposição mínima estimada para esta seqüência é de 0,3 m/1000 anos. Considerando-se válidas as inferências feitas a partir dos trabalhos de Azevedo Jr. (1991) e Silva (1992), o fundo marinho atual das plataformas interna e média pode ser composto por sedimentos da seqüência SIII, superficialmente retrabalhados durante sua exposição subaérea do final do Pleistoceno e início do Holoceno, como já sugerido por Kowsmann \& Costa (1979 a,b), ao caracterizá-los como sedimentos relictos.

A seqüência SIV, por sua vez, é só detectada nos perfis sísmicos, após a isobatimétrica de cerca de 120 m e possui clinoformas progradando em direção ao talude em conformidade com a seqüência III e a discordância DIV. Considerando a seqüência evolutiva da área estudada, supõe-se que ela tenha sua formação relacionada às oscilações do nível do mar ocorridas após 123.000 anos A.P. e que o seu topo, o fundo marinho atual, com gradiente quase plano, porém, rugoso e com sedimentos composto de sedimentos carbonáticos (fragmentos de conchas e briozoários predominantemente) indiquem um ambiente de mar calmo, pro- 


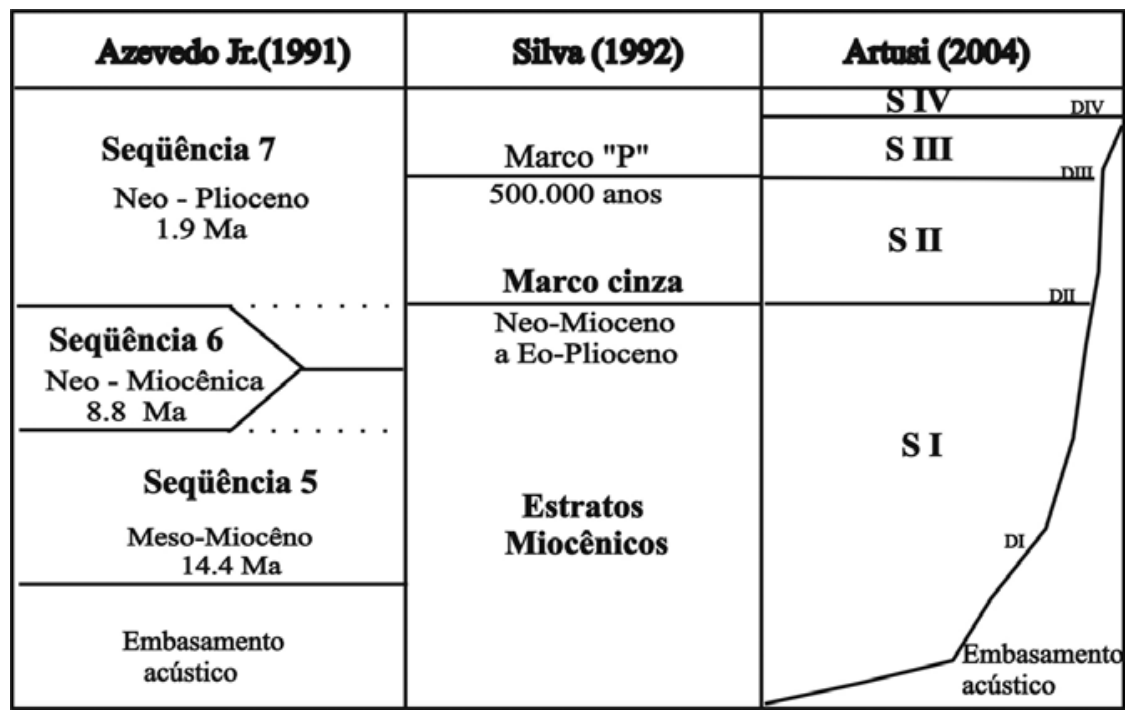

Figura 4 - Esquema comparativo das seqüências sedimentares identificadas por Azevedo Jr. (1991), Silva (1992) e Artusi (2004).

vavelmente há 16.000 anos A.P. conforme a curva de variação do nível do mar de Corrêa (1990).

\section{Paleocanais}

Neste trabalho será considerado paleocanal, a estrutura de corte e preenchimento da superfície erosiva que ocorre em subsuperfície e que foi identificada no perfil sísmico.

A interpretação das linhas sísmicas 3 e 4 da comissão Diadorim permitiu a identificação de vinte e nove paleocanais incisos nos sedimentos da seqüência SIII. Estes paleocanais possuem $190 \mathrm{~m}$ de largura e $15 \mathrm{~m}$ de profundidade, em média (Figs. 3 e 5 ).

Três paleocanais incisos na seqüência SIII foram identificados na linha sísmica 3 (paleocanais 27, 28 e 29 das Figs. 3 e 5a). Tais canais podem indicar a exposição da plataforma média quando 0 nível do mar esteve $100 \mathrm{~m}$ abaixo do nível atual entre 16.000 e 18.000 anos A.P., com base na curva de Corrêa (1990). Assim com base nas localizações destes paleocanais, sua possível correlação com as variações do nível do mar e na suposição de Kowsmann \& Costa (1979 a, b) sobre a existência de sedimentos relictos na plataforma atual, sugere-se que 0 cordão arenoso Pleistocênico da porção interna da laguna de Araruama, descrito por Martin et al. (1997), seja composto por sedimentos da seqüência SIII de idade relativa mínima de 123.000 anos A.P. (Fig. 6).

Vinte e seis paleocanais foram identificados pela análise do perfil sísmico da linha 4, numa ocorrência média de 1 paleocanal a cada 1,8 km (Figs. 2 e 5). Para o estudo da correlação das profundidades das incisões dos paleocanais com as variações do nível do mar, foram inseridas em gráfico as profundidades máximas dos talvegues dos paleocanais, medidas em relação ao nível do mar atual. Desta forma, é possível distinguir três níveis distintos de incisão (Fig. 5c). 0 nível mais profundo, a cerca de 120 m abaixo do nível do mar atual, é representado apenas pelo paleocanal 1. 0 segundo nível de incisão está na faixa de $80 \mathrm{~m}$ a $95 \mathrm{~m}$ e compreende os paleocanais 6, 7, 8, 9, 10, 11 e 18. 0 terceiro nível de paleocanais entre $60 \mathrm{~m}$ e $80 \mathrm{~m}$, compreende os paleocanais $2,3,4,5,12,13,14,15,16,17,19,20,21,22$, 23, 24, 25 e 26. De maneira geral, existe uma tendência das profundidades das incisões serem mais rasas para oeste, ao mesmo tempo em que a profundidade dos paleocanais apresenta pouca variação (Fig. 5).

Quanto às possíveis origens do paleocanais, descartou-se a possibilidade de serem formados pela ação das marés unicamente, pois, ao se comparar as características desses paleocanais com os canais atuais da costa SE dos EUA estudados por Oertel et al. (1991), verificou-se a maior freqüência de ocorrência (2,52 canais por $\mathrm{km}$ ), e maiores larguras aparentes (de $50 \mathrm{~m}$ a $1700 \mathrm{~m}$ ). A origem fluvial para os paleocanais fica limitada pela reduzida bacia de drenagem que deságua atualmente na laguna de Araruama, (cerca de $291 \mathrm{~km}^{2}$ segundo Lessa, 1990). Além disso, caso os paleocanais tivessem ligações com a drenagem emersa deveria haver rompimentos do cordão Pleistocênico da laguna de Araruama. Essas descontinuidades no cordão Pleistocênico já foram sugeridas por Guerra (1993), para explicar a 


\begin{tabular}{|c|c|c|c|c|c|}
\hline $\begin{array}{c}\text { Num. } \\
\text { do } \\
\text { canal }\end{array}$ & $\begin{array}{c}\text { Longitude } \\
\text { (g.m.s) }\end{array}$ & $\begin{array}{c}\text { Latitude } \\
\text { (g.m.s) }\end{array}$ & $\begin{array}{c}\text { Prof. do } \\
\text { paleo-canal } \\
\text { (m) }\end{array}$ & $\begin{array}{c}\text { Largura } \\
\text { do paleo- } \\
\text { canal (m) }\end{array}$ & $\begin{array}{c}\text { Espessura } \\
\text { sedimentos } \\
\text { (m) }\end{array}$ \\
\hline 1 & -42.03 .14 & -22.58 .42 & 25 & 175 & 50 \\
\hline 2 & -42.03 .44 & -22.58 .42 & 20 & 205 & 10 \\
\hline 3 & -42.04 .05 & -22.58 .66 & 15 & 160 & 10 \\
\hline 4 & -42.11 .42 & -22.58 .40 & 15 & 160 & 10 \\
\hline 5 & -42.04 .28 & -22.58 .36 & 15 & 140 & 11 \\
\hline 6 & -42.05 .35 & -22.58 .42 & 15 & 205 & 30 \\
\hline 7 & -42.06 .01 & -22.58 .43 & 15 & 260 & 30 \\
\hline 8 & -42.07 .54 & -22.58 .33 & 20 & 385 & 25 \\
\hline 9 & -42.09 .43 & -22.58 .41 & 15 & 140 & 25 \\
\hline 10 & -42.10 .23 & -22.58 .44 & 20 & 300 & 25 \\
\hline 11 & -42.11 .40 & -22.58 .50 & 10 & 160 & 35 \\
\hline 12 & -42.16 .35 & -22.58 .46 & 20 & 80 & 5 \\
\hline 13 & -42.17 .02 & -22.58 .49 & 15 & 270 & 10 \\
\hline 14 & -42.18 .30 & -22.58 .54 & 15 & 180 & 10 \\
\hline 15 & -42.21 .53 & -22.59 .06 & 15 & 180 & 5 \\
\hline 16 & -42.22 .22 & -22.59 .02 & 15 & 130 & 10 \\
\hline 17 & -42.22 .28 & -22.59 .02 & 15 & 140 & 10 \\
\hline 18 & -42.22 .36 & -22.59 .04 & 25 & 315 & 10 \\
\hline 19 & -42.25 .46 & -22.58 .57 & 20 & 160 & $<5$ \\
\hline 20 & -42.25 .51 & -22.58 .57 & 10 & 110 & 10 \\
\hline 21 & -42.26 .07 & -22.58 .54 & 20 & 200 & $<5$ \\
\hline 22 & -42.26 .36 & -22.58 .53 & 10 & 250 & 10 \\
\hline 23 & -42.26 .45 & -22.58 .54 & 10 & 95 & 11 \\
\hline 24 & -42.26 .46 & -22.58 .54 & 5 & 120 & 10 \\
\hline 25 & -42.26 .42 & -22.58 .54 & 10 & 215 & 10 \\
\hline 26 & -42.27 .25 & -22.58 .52 & 10 & 360 & 5 \\
\hline 27 & -42.29 .02 & -23.07 .56 & 10 & 120 & 20 \\
\hline 28 & -42.28 .30 & -23.09 .56 & 20 & 150 & 10 \\
\hline 29 & -42.28 .28 & -23.10 .19 & 10 & 120 & 5 \\
\hline & & & & & \\
\hline
\end{tabular}

(A)

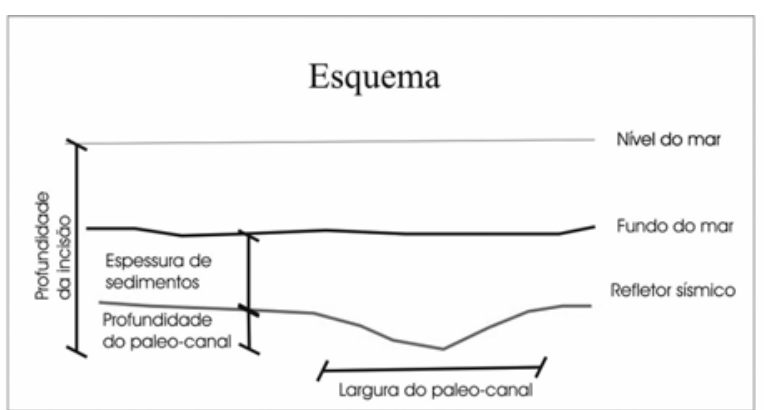

(B)

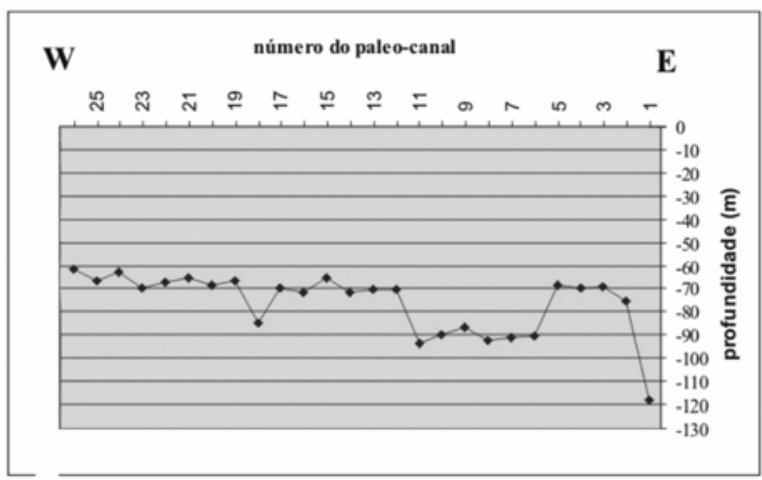

(C)

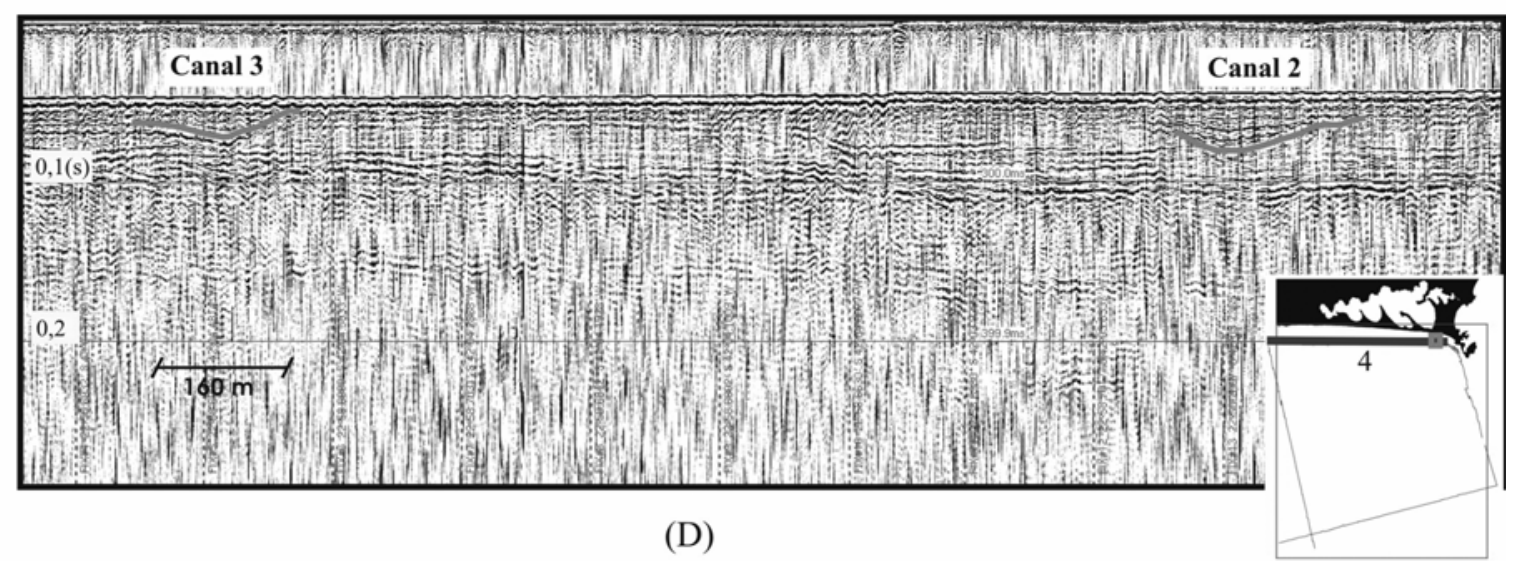

Figura 5 - (a) Localização e dimensões dos paleocanais mapeados na linha 4 (de 1 a 26) e na linha 3 (de 27 a 29 ). (b) Esquema das dimensões dos paleocanais indicados na Fig. 4(a). (c) Profundidade dos talvegues dos paleocanais observados na linha 4 da comissão Diadorim, distribuídos de acordo com sua ocorrência no perfil. 0 nível 0 (m) é o nível do mar atual. (d) Seção sísmica da linha 4 mostrando os paleocanais 2 e 3. Na seção sísmica, 0 tempo é duplo. 


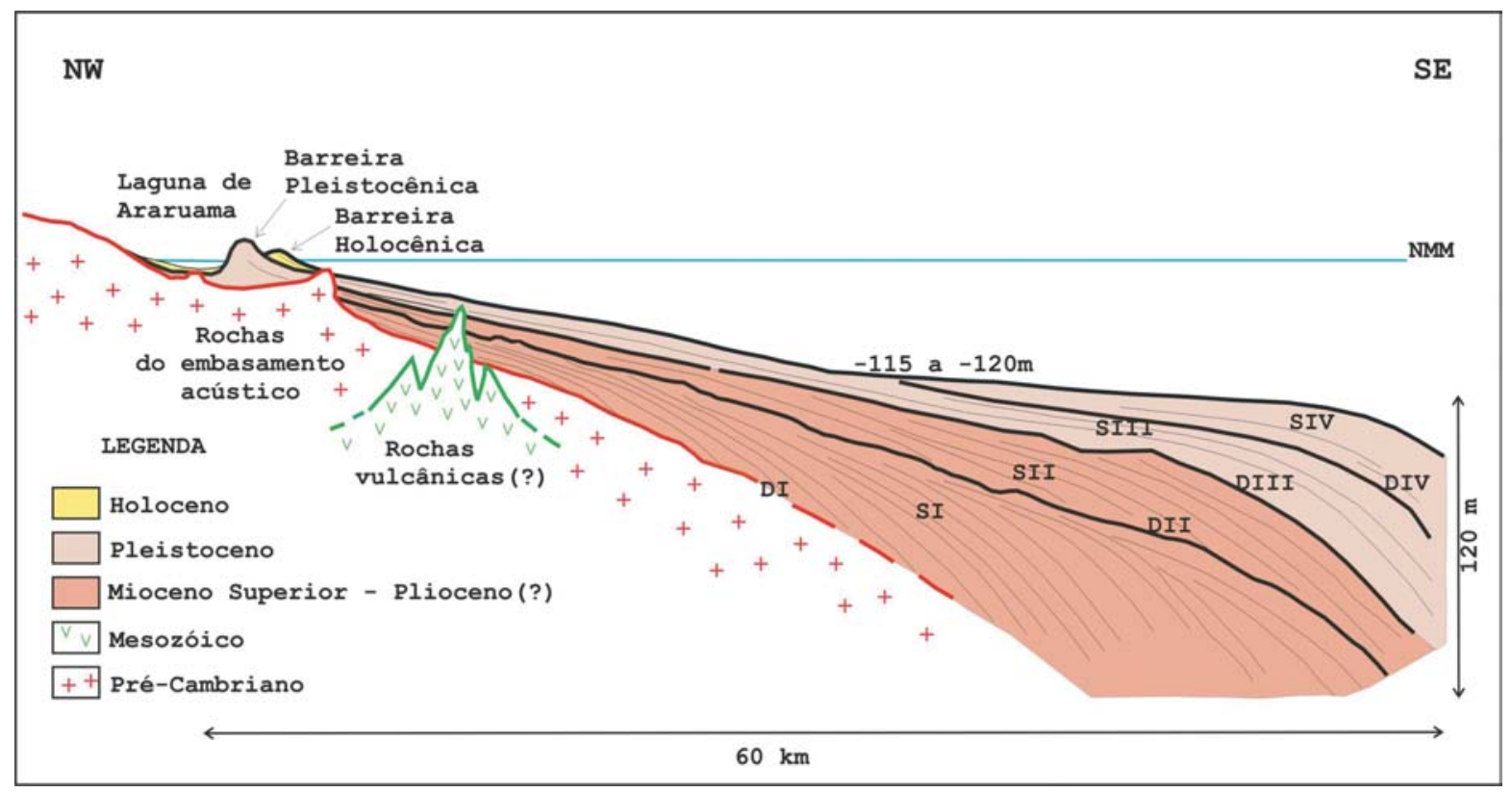

Figura 6 - Esquema sintético da estratigrafia sugerida para área de estudo, inferindo as idades das seqüências a partir dos estudos de Azevedo Jr. (1991), Silva (1992) e Martin et al. (1997).

distribuição das assembléias de minerais pesados encontradas na plataforma continental interna desta área, porém, Muehe (1994) descreveu apenas uma descontinuidade na barreira, na ponta da Acaíra, entre as enseadas da Figueira e da Gaivota, tornando, desta forma, esta hipótese improvável. Uma possibilidade para formação destes paleocanais é apresentada por Nummedal et al. (1977). Seus estudos mostram que, em ambientes dominados por ondas, semelhantes aos da plataforma adjacente à laguna de Araruama, há uma pequena quantidade de canais por km, onde os canais maiores estão associados com bacias de drenagem enquanto que os canais menores estão associados com a migração de canais em ilhas barreiras. Estes canais menores, segundo Nummedal et al. (1977), podem se formar durante tempestades e sua evolução dependerá das correntes de marés que os manterão ou não abertos para as trocas entre a laguna e o oceano. Na linha de costa atual entre Niterói e Arraial do Cabo há apenas os canais de Itaipuaçú, de Itaipu, de Ponta Negra e Saquarema, este último na área de estudo propriamente dita. Eles são canais de maré que fazem comunicação de lagunas com o oceano e são artificialmente mantidos abertos, ou então têm sua abertura favorecida pela existência de rochas cristalinas na sua desembocadura. Além disso, a diminuição das profundidades das incisões dos paleocanais (Fig. $5 \mathrm{c}$ ), pode indicar a migração para oeste, de poucos canais ao longo do Quaternário. Outra possibilidade para origem dos paleocanais é a apresentada por Molina et al. (2000) que, ao estudar a plataforma continental espanhola, identificou canais atuais e concluiu que eles podem resultar das correntes de retorno geradas durante as tempestades.

\section{CONCLUSÕES}

A morfologia do embasamento acústico, delimitado até a plataforma média sugere que ele seja composto pelas rochas metamórficas pré-Cambrianas do Complexo da Região dos Lagos e de vulcânicas Mesozóicas, semelhantes às encontradas na ilha do Cabo Frio. Estudos geofísicos futuros utilizando os métodos potenciais poderão esclarecer este ponto. A discordância DI limita 0 embasamento acústico e o pacote sedimentar sobrejacente. A análise do pacote sedimentar possibilitou identificar quatro seqüências sísmicas (SI, SII SIII e SIV), as quais foram tentativamente correlacionadas com aquelas encontradas por Azevedo Jr. (1991) e Silva (1992). Assim, sugere-se que no Neo-Mioceno houve a formação da seqüência SI e o abaixamento do nível do mar ocorrido no Neo-Mioceno a Eo-Plioceno foi o responsável pela formação da discordância erosiva DII. A seqüência II, com suas características progradantes, semelhantes às da seqüência SI provavelmente esteja relacionada ou ao evento de descida do nível do mar que antecedeu à formação do marco "P" (500.000 anos) ou então à descida do nível do mar do Pleistoceno médio (cerca de 1,5 Ma.), se comparada com a curva de Vail et al. 
(1977). Caso se confirme a hipótese da discordância DIII ser o prolongamento do marco "P", então os sedimentos depositados durante o rebaixamento do nível do mar há cerca de 1,5 Ma. devem ter sido totalmente removidos, pois, não foram detectados nos perfis analisados. A seqüência SIII, com clinoformas suavemente progradando em direção ao talude, mostram uma condição de deposição distinta das anteriores. Sugere-se que a sua formação esteja relacionada com o abaixamento do nível do mar há 123.000 anos A.P. Incisos na seqüência SIII foram observados paleocanais que podem indicar a exposição da plataforma continental nesta época. Trabalhos anteriores tanto na plataforma continental como na barreira arenosa interna da laguna de Araruama, permitem sugerir que os sedimentos do topo da seqüência SIII componham a barreira arenosa Pleistocênica daquela laguna. A discordância DIV, por não apresentar evidências de erosão, pode representar uma estabilização do nível do mar após a descida de $120 \mathrm{~m}$ abaixo do atual, permitindo, desta forma, a formação da seqüência SIV, em conformidade com a seqüência SIII. Ainda com base nos trabalhos pretéritos, sugere-se que as variações do nível do mar ocorridas no Holoceno podem ser responsáveis além do retrabalhamento dos sedimentos superficiais da plataforma continental interna e média e da formação da barreira arenosa, com 0 fechamento da laguna de Araruama serem os responsáveis pela formação e/ou preenchimento dos paleocanais identificados nas linhas sísmicas 3 e 4 . Quanto aos processos responsáveis pela origem desses paleocanais, sugere-se que eles resultem da migração de algumas antigas ligações da laguna de Araruama com o mar, ou então que eles sejam resultado de correntes de retorno geradas pelas tempestades. Estudos mais aprofundados tanto da barreira interna da laguna de Araruama identificando descontinuidades como da dinâmica das correntes atuantes na plataforma interna, poderão definir os processos atuantes e as feições resultantes nesta área.

\section{AGRADECIMENTOS}

Os autores agradecem ao LAGEMAR, UFF pelo apoio e disponibilidade dos equipamentos de sísmica; à Subsea7 pelo empréstimo de parte dos equipamentos de sísmica, em especial agradecemos ao técnico Sr. Paulo Cezar do Rego. Ao IEAPM/MB, somos gratos pelo apoio logístico durante a coleta dos dados sísmicos.

\section{REFERÊNCIAS}

ALVES EC, SPERLE M, MELLO SLM \& SICHEL SE. 1997. Compartimentação tectônica do sudeste do Brasil e suas relações com as zonas de fraturas oceânicas. 5th International Congress of the Brazilian Geophysical Society, São Paulo - SP, 1: 48-50.
ARTUSI L. 2004. Geologia, geomorfologia e sismoestratigrafia rasa da plataforma continental ao largo da laguna de Araruama - RJ. Universidade Federal Fluminense - UFF. Niterói, RJ. (Dissertação de Mestrado). $91 \mathrm{p}$.

ASMUS HE. 1984. Inferências, hipóteses e problemas relativos à origem e evolução da margem continental brasileira. XXXIII Congresso Brasileiro de Geologia, Rio de Janeiro - RJ. p. 1655-1677.

AZEVEDO Jr MF. 1991. Integração entre o preenchimento sedimentar Cenozóico das bacias de Campos e Santos e a evolução tectônica e geomorfológica das áreas continentais adjacentes. Departamento de Geologia da Escola de Minas. Universidade Federal de Ouro Preto, Ouro Preto - MG, (Dissertação de Mestrado). 159 p.

CORRÊA ICS. 1990. Analyse morphostructurale et évolution paléogéographique de la plate-forme continentale Atlantique sud-brésilienne (Rio Grande do Sul - Brésil). L'Université de Bordeaux I, Bordeaux, Franç̧a. (Tese de Doutoramento). $314 \mathrm{p}$.

DIAS MS. 1997. Significado tectônico da topografia do sudeste do Brasil e suas prováveis relações com a margem continental adjacente. Observatório Nacional - ON. Rio de Janeiro - RJ. (Tese de Doutoramento). $169 \mathrm{p}$.

FERRARI AL. 2001. Evolução tectônica do graben da Guanabara. Instituto de Geociências. Universidade de São Paulo. São Paulo. (Tese de Doutoramento). $409 \mathrm{p}$.

FONSECA MJG, HEILBRON M \& CHRISPIM S. 1984. Geologia estrutural da área de Cabo Frio e Armação dos Búzios. XXXIII Congresso Brasileiro de Geologia, Rio de Janeiro - RJ, 13: 5393-5424.

GORINI MA, ALVES E \& PONZI VRA. 1984. Considerações sobre a margem continental sudeste brasileira com implicações sobre a história geológica da Serra do Mar. XXXIII Congresso Brasileiro de Geologia, Rio de Janeiro - RJ. (Resumos). p. 88.

GUERRA JV. 1993. Minerais pesados como indicadores de paleodrenagens e direção de transporte de sedimentos na plataforma continental interna entre Saquarema e Arraial do Cabo-RJ. Instituto de Geociências, Universidade Federal do Rio de Janeiro - UFRJ, Rio de Janeiro - RJ. (Dissertação de Mestrado). 104 p.

KOWSMANN RO \& COSTA MPA. 1979a. Sedimentação Quaternária na margem continental brasileira e das áreas oceânicas adjacentes. PETROBRAS/DNPM/CPRM/DHN/CNPq. Rio de Janeiro-RJ. (Série Projeto REMAC 8). p. 22-42.

KOWSMANN RO \& COSTA MPA. 1979b. Bancos arenosos holocênicos da plataforma continental brasileira: gênese e potencial mineral. Rio de Janeiro, CPRM. 25 p.

KUMAR N, GAMBÔA LAP, SCHREIBER BC \& MASCLE J. 1977. Geologic history and origin of São Paulo plateau southeastern Brazilian margin, comparison with the Angolan margin, and the early evolution of the northern South Atlantic. In: SUPKO PR \& PERCH-NIELSEN K et al. Initial 
Reports of the Deep Sea Drilling Project. Washington, U.S. Government printing Office, v. XXXIX, p. 927-945.

LESSA CG. 1990. Hidrografia e sedimentação do canal de Itajurú Laguna de Araruama (RJ). Departamento de Geografia - Universidade Federal do Rio de Janeiro - UFRJ. Rio de Janeiro, RJ. (Dissertação de Mestrado). 109 p.

LOPES ALM. 2004. Análise da evolução sedimentar quaternária da plataforma continental sul da bacia de Campos com base em estratigrafia sísmica e sonografia. Universidade Federal Fluminense - UFF. Niterói, RJ. (Dissertação de Mestrado). 68 p.

MARTIN L, SUGUIO K, DOMINGUEZ JML \& FLEXOR J-M. 1997. Geologia do Quaternário costeiro do litoral norte do Rio de Janeiro e do Espírito Santo. CPRM/FAPESP, Belo Horizonte - MG, 112 p. 2 mapas.

MOLINA FJH, SALAS LMF, LOBO F, SOMOZA L, DÍAZ-DEL-RIO V \& DÍAZ JMA. 2000. The infralittoral prograding wedge: a new largescale progradational sedimentary body in shallow marine environments. Geo-Marine Letters, 20: 109-117.

MUEHE D \& CARVALHO VG. 1993. Geomorfologia, cobertura sedimentar e transporte de sedimentos na plataforma continental interna entre a Ponta de Saquarema e o Cabo Frio (RJ). Boletim do Instituto Oceanográfico, 41: 1-12.

MUEHE D. 1994. Lagoa de Araruama: geomorfologia e sedimentação. Cadernos de Geociências - Rio de Janeiro - RJ, 10: 53-62.
NUMMEDAL D, OERTEL GF, HUBBARD DK \& HINE AC. 1977. Tidal inlet variability - Cape Hatteras to Cape Canaveral. In: Proceedings Coastal Sediments 77. American Society for Civil Engineers, Charleston, SC, p. 543-562.

OERTEL GF, HENRY VJ \& FOYLE AM. 1991. Implications of tidedominated lagoonal processes on the preservation of buried channels on a sediment-starved continental shelf. In: SWIFT DJP, OERTEL GF, TILLMAN RW \& THORNE JA (Ed.). Shelf Sand and Sandstone Bodies. Geometry, facies and sequence stratigraphy. Special Publication no. 14 of the International Association of Sedimentologists. Blackwell Scientific Publications. Cambridge, USA, p. 379-393.

SILVA A. 1992. Evolução sedimentar pós-Miocênica na área nordeste da bacia de Campos. Departamento de Geologia, Universidade Federal do Rio de Janeiro - UFRJ. Rio de Janeiro - RJ. (Dissertação de Mestrado). $70 \mathrm{p}$.

VAIL PR, MITCHUM Jr RM \& THOMPSON S. 1977. Seismic stratigraphy and global changes of sea level, part 4: global cycles of relative changes of sea level. In: PAYTON CE (Ed.). Seismic Stratigraphy- applications to hydrocarbon exploration. American Association of Petroleum Geologists. Tulsa, Oklahoma. U.S.A. p. 83-96.

VIVIERS MC \& AZEVEDO RLM. 1988. The southeastern area of the Brazilian continental margin: its evolution during the Middle and Late cretaceous as indicated by paleoecological data. Revista Brasileira de Geociências. 18: 291-298.

\section{NOTAS SOBRE OS AUTORES}

Lucia Artusi. Geóloga pela UNISINOS (1986). Mestre em Geologia e Geofísica Marinha pelo LAGEMAR/UFF (2004). De 1990 até o presente momento atua no Instituto de Estudos do Mar Almirante Paulo Moreira - IEAPM, em atividades de pesquisa do fundo marinho raso da plataforma continental, visando atender às necessidades do setor Operativo da Marinha do Brasil.

Alberto Garcia de Figueiredo Jr. Geólogo pela UFRJ (1972), mestrado pela UFRGS (1975), doutorado pela Universidade de Miami (1984), pós-doutorado pela SUNY (1990), Professor Titular do Departamento de Geologia, UFF, líder do Grupo de Pesquisa LAGEMAR, pesquisador 1 CNPq. 